\title{
Produção de espelhos parabólicos e construção do conceito de função polinomial de $2^{\circ}$ grau
}

\author{
Production of parabolic mirrors and construction of the concept of 2nd degree polynomial function
}

\author{
Marco Aurélio Torres Rodrigues*1, Luiz Fernando Mackedanz ${ }^{2}$ \\ ${ }^{1}$ Universidade Estadual do Rio Grande do Sul, Unidade Santana do Livramento, Porto Alegre, Rio Grande do Sul, RS, Brasil \\ ${ }^{2}$ Universidade Federal do Rio Grande, Rio Grande, RS, Brasil
}

Recebido em 22 de Fevereiro, 2017. Revisado em 02 de Maio, 2017. Aceito em 13 de Junho, 2017.

\begin{abstract}
Um dos maiores obstáculos para aprender Física no Ensino Médio é, segundo o relato dos professores, sua abordagem matemática. Neste trabalho propomos uma atividade que integra conteúdos de física e matemática, de forma a tornar a função quadrática significativa para os estudantes. Relatamos as atividades planejadas e aplicadas em sala de aula, com alunos do $1^{\circ}$ ano do Ensino Médio de uma escola pública situada no interior do RS. As atividades referiam-se a produção de espelhos parabólicos em dois modelos diferentes, e na sequência a construção do conceito de função polinomial de 20 grau (a chamada função quadrática). Foram utilizados tanto o espaço da sala de aula como o espaço da casa dos estudantes, permitindo vivenciar a aprendizagem durante o tempo que a atividade durou. Trabalhamos com a metodologia construtivista. Concluímos que tal classe de atividades, denominadas hands-on, realmente conseguem trazer significância para os conceitos normalmente abordados de forma abstrata nos livros didáticos.
\end{abstract}

Palavras-chave: Óptica Geométrica, funções matemáticas, contextualização.

\begin{abstract}
One of the biggest obstacles to learn physics in High School is, according teachers' account, their mathematical approach. In this paper we propose an activity that integrates Physics and Math contents, in order to make quadratic function significant for the students. We report the activities planned and implemented in the classroom, with High School 1st year students in a public school located within the RS. The activities referred to the production of parabolic mirrors in two different models, followed by the construction of the concept of 2 nd degree polynomial (the so called quadratic function). Therefore, we used both the classroom space and students' home space, allowing experience learning during the period that lasted the activity. We work under a constructivist methodology. We conclude that such activities class, called hands-on, can really bring significance to the concepts usually covered abstractly in textbooks.
\end{abstract}

Keywords: Geometric Optics, mathematical functions, contextualization.

\section{Introdução}

A integração entre a Física e a Matemática aparece frequentemente nos livros didáticos, tratando esta última como uma ferramenta, e não na forma que gostaríamos, como uma linguagem da natureza. Para ilustrar seu uso desta forma, devemos procurar atividades que permitam utilizar fenômenos físicos para construir significados matemáticos. Sobre isso, Menezes [1] relata:

A Matemática tem funcionado como uma espécie de metaciência, na medida em que perpassa e estrutura muitas outras ciências.

A Matemática tem mesmo sido apelidada, por diversos autores, de linguagem universal da ciência, sendo ela mesma detentora de uma linguagem própria que permite a comunicação entre os iniciados [p. 1]

*Endereço de correspondência: profmarcotorresjbsegv@gmail.com
Portanto, ao tratar a Matemática como linguagem estruturante, ou como "metaciência", podemos eliminar os limites das grandes áreas de conhecimento, conforme propostas pela Matriz Curricular do Exame Nacional do Ensino Médio - ENEM [2], atuando desta forma interdisciplinarmente, como pretendido pelo mesmo documento. Notem que esta simples mudança de paradigma coloca a Matemática e as Linguagens em pé de igualdade, e possibilita tratar ambas em termos de letramentos [3].

Contudo, o uso da Matemática como linguagem estruturante traz problemas no entendimento da Física. Podemos afirmar que o conhecimento físico da natureza permite a resolução de problemas diversos associados ao ambiente natural, e para isso é necessário, ao estudá-lo, ter proficiência tanto na parte de interpretação de texto, quanto em sua tradução para a linguagem matemática. No entanto, o princípio da disciplina de Ciências, na Grã-Bretanha do século XIX, era o entendimento de processos naturais cotidianos aos estudantes [4]. A virada 
para o uso mais disseminado de Matemática no ensino de Ciências ocorre com a ascensão de J D Forbes, em 1883, ao cargo de professor de Filosofia Natural na Universidade de Edimburgo, na Escócia. Apoiado por um grande grupo de matemáticos de Cambridge, ele substituiu a visão tradicional escocesa, de ensinar ciências de forma mais próxima ao cotidiano, por uma descrição matemática dos processos naturais, mais próxima à pesquisa [5].

Aqui convém ressaltarmos que não estamos nos opondo ao uso da Matemática como linguagem na Ciência, e da atual necessidade de aproximar ensino e pesquisa, dada a vasta gama de processos tecnológicos que fazem parte de nosso cotidiano. Mas, apesar da necessidade de descrições acuradas para entender profundamente estes processos, é percebido que, na parte do ensino de Física, em especial, o tratamento matemático introduz um viés ao aprendizado. Um exemplo claro pode ser encontrado nos livros didáticos de Física, no Ensino Médio, e nos textos a respeito desta área nos livros de Ciências do Ensino Fundamental. Apesar da preocupação atual de tornar esta ciência mais fenomenológica, ainda existe um excesso de matemática na apresentação das situações.

Historicamente, o livro didático traz o processo de matematização levando-o às últimas consequências, muitas vezes deixando o espaço do fenômeno para o tratamento matemático [6]. Como professores de Física, nossa atração pela fenomenologia leva a um caminho inverso. Podemos nos espelhar nas demais Ciências da Natureza que, apesar de estruturadas pela Matemática e pela Geometria, discutem seus princípios baseados na experimentação e observação dos fenômenos, deixando, em nível de educação básica, a matematização de lado. Convém ainda destacar que, com isso, não estamos querendo simplesmente abandonar a formulação matemática das leis da Natureza, uma vez que o completo entendimento de processos e fenômenos, de forma a gerar inovação e conhecimento, necessita da modelagem dos mesmos, e isto inclui a Matemática.

Assim, escolher assuntos típicos dos livros didáticos e usá-los na construção do conhecimento matemático torna este aprendizado mais participativo e com indicações fortes de significatividade. Ainda mais importante é a referência a atividades "hands-on", onde o estudante é o principal agente de sua aprendizagem, cabendo ao professor a mediação pedagógica [7]. Neste tipo de atividade, a problematização, a observação, a reflexão e a resolução de problemas oportunizam ao estudante perceber sua própria evolução no aprendizado, sem ser avaliado por outra pessoa. Aqui, a crítica traz a significatividade.

Neste processo, a escolha da atividade por parte do professor-mediador traz profundos impactos na aprendizagem dos alunos. Ao propor questionamentos que não são limitados a uma única disciplina, mas possuem interfaces perceptíveis com outras, o professor permite a evolução de um conhecimento integrado, podendo ser visto como sistêmico, se focado nas relações entre as áreas, ou complexo, se percebido pelos níveis de interação do conhecimento com o estudante. No presente trabalho, escolhemos a construção de espelhos parabólicos como um tema gerador para a construção da representação matemática, permitindo a aproximação entre a Óptica Geométrica e o Estudo de Funções Matemáticas - no caso, a função quadrática - dando significado a estas. Um aspecto que reforçou o desejo de propor a construção de espelhos parabólicos foi a possibilidade de buscar respostas significativas para indagações básicas e rotineiras que os educandos sempre apresentam: "por que estudo isto?", "Para que serve aquilo?". Defendemos que tais respostas podem ser atingidas ao longo da execução do trabalho.

Nosso trabalho está assim constituído: na seção 2, apresentamos breves discussões sobre o ensino de Óptica Geométrica - por parte da Física - e de Funções Quadráticas - por parte da Matemática, além de defender o uso de atividades que integrem disciplinas, de forma a construir possibilidades interdisciplinares aos estudantes, o que constitui basicamente uma revisão bibliográfica, além de apresentarmos o referencial teórico utilizado. Na seção 3 , apresentamos a proposta de trabalho, mostrando de forma detalhada o processo de construção e seus espaços de problematização, discussão, reflexão e ação. A seção 4 é dedicada às análises do trabalho e das impressões coletadas com os estudantes, utilizando a análise temática [8]. Finalizamos com nossas conclusões e apontando perspectivas para o trabalho.

\section{Revisão bibliográfica e referencial teórico}

\subsection{Revisão bibliográfica}

Percebemos que o valor significativo dado ao ato de aprender, e por consequência transformar, foi gradativamente conquistado, devido as necessidades humanas. Para que este aprendizado ocorra, um contribuinte significativo é indispensável: o professor. Não basta ser um professor competente, dominar o conteúdo, ele precisa encontrar condições, promover situações onde realmente ocorra a aprendizagem. Professor com competência é aquele que ensina o aluno a aprender a aprender [9]. Para isso podemos apelar para o lado afetivo, para o lado da responsabilidade, ou - o mais significativo - mostrar comprometimento com os mesmos. É notório que alunos bem orientados consigam êxito em seus estudos.

Geralmente, esperamos de um professor características como competência na sua especialidade; conhecimento da matéria; habilidade em tratar com os alunos; capacidade de motivação; espírito cooperativo e produtivo. Enquanto isso, boa parte dos professores é previsível, não nos surpreende; repete fórmulas, sínteses [10]. A grande possibilidade de mudança nas práticas pedagógicas, e diretamente na aprendizagem, está em educar e revitalizar o educador. Neste trabalho, abordamos sob o ponto de vista da inovação pedagógica [11] tal mudança, 
e relatamos o caso da aplicação no ensino de física e matemática.

Em geral, o estudo de espelhos, lentes e fenômenos relacionados, é abordado sob o ponto de vista matemático, especialmente geométrico. Apesar disso, a Óptica está relacionada ao estudo da luz, e como tal, pode ser considerada como um ramo do Eletromagnetismo, uma vez que a grande unificação que surge das Equações de Maxwell coloca na mesma descrição (como onda eletromagnética) fenômenos elétricos, magnéticos e luminosos. Na forma como está inserida no livro didático do Ensino Médio, porém, pouco se relaciona às ondas eletromagnéticas, restando apenas um tratamento excessivamente geométrico e matemático - o que se convencionou denominar Óptica Geométrica. Isso não impede propostas inovadoras nesta parte da Física, visando aprendizagem ativa [12], ou envolvendo História e Filosofia da Ciência [13-14]. Além disso, podemos destacar os paralelos entre o ensino da óptica para o entendimento de processos como a visão [14], apesar de ser uma área propensa a uma grande variedade de concepções alternativas, sejam ultrapassadas ou errôneas [15].

Pelo desenvolvimento do estudo de espelhos e lentes desde a Antiguidade, possivelmente sendo rastreado até Euclides, no século III a.C. [13], existe espaço para muitas concepções alternativas, que já foram consideradas como verdades científicas e o aprofundamento dos estudos fez com que fossem desconsideradas [14-15]. Assim, estudar os princípios históricos, quer via Princípio de Heron [14], quer via Princípio de Fermat, para o caminho óptico, nos permite entender a evolução da ciência, ou quais eram as concepções relacionadas à natureza da luz [13] ou da visão [14]. Por outro lado, a montagem de experimentos envolvendo fenômenos ópticos permite aos estudantes engajarem-se de forma mais efetiva nas pesquisas e na construção do seu conhecimento. Ou seja, apesar do enfoque matemático, os experimentos de Óptica Geométrica estão carregados de fenômenos observacionais, que emponderam o aluno como agente ativo de sua aprendizagem [12].

Podemos perceber, a partir do livro didático, que o ensino de Óptica no Ensino Médio está fortemente atrelado aos conceitos geométricos. O ramo da Óptica Física, que trata a luz como onda eletromagnética e assim pode ser considerada como uma extensão (ou área) do Eletromagnetismo, é pouco tratado antes do Ensino Superior, apesar de sua necessidade para explicar um grande número de fenômenos físicos observados no cotidiano. Devido a esta forte ligação com os conceitos matemáticos, tanto da Geometria como do estudo de funções, podemos vislumbrar uma possibilidade de aproximação dos conteúdos destas duas disciplinas, de forma significativa.

Por outro lado, devemos ter presente que o ensino de Matemática tem se esforçado para trazer significado para os conteúdos estudados. Para o presente artigo, escolhemos o ensino de funções, em especial a função quadrática. Santos Júnior defende a necessidade de uma abordagem cognitiva [16], ancorada na teoria dos campos conceituais [17], em busca de invariantes operatórios entre alunos do $1^{\circ}$ ano do Ensino Médio, em especial aqueles associados à construção do gráfico representativo da função estudada.

Para poder verificar de forma mais detalhada a construção de funções, alguns autores utilizam recursos computacionais para o ensino. Sousa apresenta a utilização do software Geogebra [18] "como uma metodologia diferenciada e o uso de uma ferramenta em que o aluno possa ter a liberdade de ver a Matemática em pleno movimento, garantindo com isso a possibilidade de perceber a importância e a essência da Matemática" (p. 20). Os alunos do $1^{\circ}$ ano do Ensino Médio, onde o produto educacional foi aplicado, alcançaram um bom entendimento do significado dos parâmetros da função quadrática, associados à concavidade e aos locais de intersecção da função com os eixos coordenados. Uma das dificuldades detectadas, porém, está na necessidade de domínio do software por parte de professor e alunos, o que dificulta avaliar de forma correta o real aprendizado com tal metodologia.

Já Souza e Silva exploram o ensino através de softwares específicos, construídos com objetivo de ensinar as funções quadráticas, com uma interface mais simplificada [19]. Neste trabalho, os autores mudaram o enfoque da construção para interpretação do gráfico, procurando estimular práticas investigativas com os estudantes. Nesta proposta, percebe-se um maior envolvimento dos estudantes, uma vez que os mesmos buscam ressignificar os conhecimentos teóricos associados às funções, e nas interpretações trazer aplicações das mesmas em seu cotidiano. Isto permite, conforme D'Ambrósio [20] "tornar a Matemática interessante, isto é, atrativa; relevante, isto é, útil; e atual, isto é, integrada no mundo de hoje" [p.15].

Uma forma de aproximar as duas áreas de ensino, e trabalhar de forma participativa, é utilizar a técnica hands-on, cuja tradução em português seria "mãos na massa". Ela foi pensada como inovação do ensino de ciências, principalmente para crianças, com o propósito de proporcionar um primeiro contato com esse campo do conhecimento, levando-as a observar, manipular, registrar e refletir sobre determinados fenômenos; em outras palavras, a ciência deve ser vivida para ser entendida [7].

Com esta técnica, o aluno constrói progressivamente competências de linguagens, tanto orais como escritas, ao mesmo tempo em que elabora o seu raciocínio. Assim, o professor poderá estimular os alunos na sala de aula a discutirem em grupos, ações que poderão solucionar um determinado problema de ciências. No caso em questão, construir um espelho parabólico.

Além disso, alguns fatores precisam ser considerados para tornar este espaço de aprendizagem mais favorável, permitindo maior aproveitamento de tempo por parte do professor e alunos. Num trabalho cooperativo, as trocas de experiências ocorrem com mais frequência do que num estudo feito unicamente a partir do professor ou mesmo no caso do estudo a partir do aluno só que 
desenvolvido. Por isso, damos preferência ao trabalho em grupo, justificado em [21]:

Observo que a maioria dos educadores organizam suas atividades de sala de aula em grupos, entretanto poucos buscam compreender o motivo dos alunos ficarem confortáveis com esta dinâmica, o que a meu ver parece ser bem simples: os alunos estão todos dentro da mesma zona de desenvolvimento real, logo o entendimento entre eles é muito mais fácil (p.42).

Continuando no contexto do trabalho em grupo, [21] também traz a contribuição de [22]:

Entretanto para utilizar a dinâmica de grupo eficazmente, dentro da teoria vigotskiana, devese escolher deixar os alunos trabalharem juntos quando na atividade de ensino tiver conteúdos e/ou habilidades a serem discutidos, quando eles terão a oportunidade de trocar ideias e ajudar-se mutuamente no trabalho coletivo (p. 42).

Ainda, o professor deve tentar viabilizar meios para despertar o interesse dos estudantes, criando uma motivação para o aprendizado, o que alguns estudantes já possuem por terem sido incentivados nos seus lares. Quanto à utilização da sala de aula na construção do conhecimento, verificamos que a maioria dos alunos prefere deixar a realização de suas tarefas escolares para casa. A organização do trabalho deve considerar seu desenvolvimento em sala de aula, deixando para casa o trabalho de pesquisa e construção de hipóteses.

De acordo com isso, devemos ter a capacidade de perceber que nosso aluno é a peça principal no quebra-cabeça da aprendizagem, o ator principal no processo. Um bom planejamento está, muitas vezes, centrado na participação do aluno, onde ele possa interagir e não simplesmente observar. Por isso, torna-se indispensável conhecer o nível cognitivo dos nossos educandos e para tanto os trabalhos em grupo tornam-se indispensáveis, pois permitem que alunos em mesmo nível de desenvolvimento proximal (NDP) trabalhem coletivamente. Existem alunos que embora estejam no mesmo ano escolar apresentam diferentes níveis de desenvolvimento real (NDR), logo discentes com índices menores nos NDR ficariam receosos, temerosos, em participar das atividades, todavia, atividades em grupos unem alunos, afinal o que esta em jogo é a NDP e não a NDR. Finalmente, sendo o aluno o próprio agente da aprendizagem, tudo que desejarmos que aprendam, habilidades que desenvolvam, conceitos a serem obtidos, devem apresentar transparentes significados para o mesmo. Por mais atraentes que possam parecer as atividades de aprendizagem propostas pelo professor, é preciso que exista pertinência do conteúdo para que os alunos queiram aprendê-lo.
Um dos aspectos que dificulta a observação do significado do conteúdo pelo aluno é o fato de o mesmo ser trabalhado isoladamente em determinada disciplina. Os documentos oficiais [23] propõem que o ensino deva ser interdisciplinar e contextualizado, apesar de não explicar o que significa a interdisciplinaridade ou como ela pode ser trabalhada. Devido a este silêncio quanto à definição, confunde-se comumente a interdisciplinaridade com a integração de conteúdos, ou com o trabalho com temáticas comuns. Apesar de não ser parte do escopo deste trabalho, chamamos a atenção que nossa visão sobre o tema nos leva a tratá-la como uma construção conjunta do espaço da sala de aula, com trocas entre alunos e professores, e entre os professores. Partimos do pressuposto que a interação é peça fundamental do trabalho interdisciplinar e, por esse motivo, não devemos definir características do ser interdisciplinar. Como este trabalho busca relatar a metodologia utilizada em sala de aula, mas com a prática de um professor apenas, não estamos propondo a interdisciplinaridade, mas sim uma tentativa de trabalhar Física e Matemática conjuntamente, para quem sabe mostrar ao aluno que ambas podem caminhar paralelamente, no mesmo sentido.

Brettas já chamou a atenção para este fato quando diz que não podemos esperar que os alunos possam descobrir, sem orientação a relação existente entre as inúmeras áreas do conhecimento [24]. Então nós precisamos acreditar que todas as ciências estão interligadas, que é muito mais fácil estudá-las todas juntas do que isolando uma das outras. Mais uma vez, percebe-se a necessidade de um trabalho interdisciplinar, no sentido da busca pela integração entre disciplinas. Como podemos perceber na próxima seção, os primeiros passos práticos para esta integração surgem ao barrarmos as divisões entre as mesmas, construindo o conhecimento dos alunos sem dividi-lo em compartimentos estanques, como o horário para Física e o horário para Matemática. Assim, com uma postura investigativa sobre a Natureza, devemos pensar em como aumentar a luz natural da razão, não com o propósito de resolver esta ou aquela dificuldade do tipo escolástico, mas para que sua compreensão possa iluminar sua vontade para sua própria escolha em todas as contingências da vida.

\subsection{Referencial Teórico}

Até o momento apresentamos uma pequena revisão bibliográfica, entretanto, a seguir indicaremos o referencial teórico utilizado na construção metodológica da proposta, para o qual adotamos o Construtivismo Científico [25,21]. Tal metodologia é alicerçada em três tópicos centrais: o papel das atividades investigativas na construção do conhecimento; o papel do professor no ensino de ciências como investigação e por último e não menos importante, as etapas indispensáveis de uma aula com caráter investigativo. 
Como relatamos uma intervenção pedagógica, vamos detalhar melhor o segundo tópico, que fundamenta a atividade proposta, pois o papel do professor é de extrema importância e este não será tratado apenas nesta seção, nas conclusões retomaremos esta discussão trazendo alguns chavões populares a respeito da metodologia construtivista, que no nosso entendimento, apenas reforçam concepções erradas a seu respeito

Rodrigues [22] afirmou que:

Nesta abordagem construtivista, o papel do professor é de extrema importância, entretanto é muito distinto do papel do professor no ensino tradicional; tal diferença fica completamente evidenciada no que tange à interpretação, à compreensão, que ambos possuem a respeito de conteúdos escolares. O professor construtivista teve a capacidade de ampliar seu entendimento a respeito do conceito de conteúdos escolares e, assim, desenvolver uma metodologia adequada, condizente com esta evolução de conceito, já o professor tradicional continua acreditando que conteúdos escolares são apenas os conteúdos que aparecem na ementa da disciplina (p. 32).

$\mathrm{O}$ autor chama a atenção para o fato de o professor tradicional, assumir, entender como conteúdos apenas fatos e conceitos, já o professor construtivista, agrega a visão tradicional, os procedimentos, as atitudes, as normas e valores. Sendo assim o professor é uma figura importantíssima nesta metodologia e deve estar atentando aos seguintes pontos: a autonomia do aluno; o papel do erro na construção do conhecimento; a cooperação entre os alunos; a avaliação; e a interação professor-aluno [25].

Rodrigues [22] nos propõe o seguinte questionamento: se todos nós educadores gostamos de estudantes autônomos porque estes não o são? E mais: o que estamos fazendo para tornar estes alunos autônomos? A metodologia construtivista aqui apresentada trabalha com a questão da autonomia do aluno, ou seja, este durante as atividades propostas deverá tomar decisões, em vários momentos os educandos decidem, todavia, conforme o autor já alertou:

(...) devemos tomar cuidado, esta autonomia deve ser construída através do estabelecimento de regras de trabalho e convivência em sala de aula, quer dizer, o começo não deve ser nada fácil. Estas regras de trabalho e convivência devem ser discutidas, negociadas entre professores e alunos, de forma que a obediência ao professor seja uma forma de cooperação (p. 33).

A construção da autonomia moral, das regras de convivência em sala de aula, é necessária para o aluno alcançar a autonomia intelectual, pois uma não existe sem a outra. Se o aluno tiver de seguir regras preestabelecidas sem liberdade de dialogar com seu professor, ele também aceitará, sem discutir e sem questionar, dar a resposta que o professor quer, ainda que pense de outra maneira [25].

Passamos, para o papel do erro. Acreditamos que a maioria de nós, hoje educadores, sofremos enquanto alunos com a questão do erro e, será que mudamos nosso entendimento a respeito do erro, ou continuamos afir- mando as práticas metodológicas e conceituais de nossos antigos professores? Não estamos aqui, querendo crucificar professores, muito menos criticar suas concepções a respeito do erro dos alunos, afinal todos os educadores "acreditam ter [...] o compromisso pedagógico de ensinar corretamente uma ciência, o erro nunca deveria aparecer e, se isso acontecesse, deveria ser corrigido imediatamente, para que ficasse bem claro o que é certo e o que é errado" [22].

Propomos este questionamento inicial, acompanhado da afirmação de Carvalho, pois para trabalhar de forma construtivista precisamos estar cientes que o erro irá aparecer inúmeras vezes e mais, precisamos saber o que fazer com ele. Dentro desta perspectiva, Rodrigues [22] contribui:

Nós, professores, não podemos ser ingênuos a ponto de acreditar que um erro pode ser apagado com uma borracha e que, mesmo acompanhado de uma explicação, o erro pode ser extinto, sanado. Pois sabemos - de nossas práticas enquanto professores - que os alunos voltam a errar, pois tais erros estão alicerçados em um conjunto de referências que parece bastante sensata para os alunos (p. 23).

Então o que nós professores temos a fazer é transformar estes erros em situações de aprendizagem, não iremos aqui avançar na tentativa de compreensão e importância do erro como fez Piaget, tratando de dois sistemas cognitivos. O que estamos tentando tornar claro é que não vamos propor uma nova concepção de entendimento do que caracteriza o erro, visto que Piaget, já nos brindou com tal concepção, faremos uso desta interpretação. Para tanto utilizaremos, o exemplo dado [22]:

Assumamos que a criança tem um problema para solucionar e, na tentativa de resolução deste, através da manipulação de objetos disponíveis, não conseguiu, pois optou por procedimentos inadequados. Entretanto a criança dispõe de uma estrutura cognitiva, afinal recorreu a alguns procedimentos, logo o erro caracteriza um não aprimoramento de conhecimentos já construídos. Nesta situação em particular, os alunos recorrem a outros grupos, isto é, a grupos que já resolveram tal tarefa, em busca da solução; num enfoque tradicional esta atitude por parte dos alunos seria inaceitável, visto que caracterizaria "cola", uma simples cópia do que os outros grupos já fizeram; já no enfoque construtivista observa-se que os alunos buscam um acerto, uma pista de um caminho alternativo, visto que já tem consciência de seu erro (p.34).

Precisamos identificar que tipos de erros estão sendo cometidos e promover condições para que estes sejam superados na íntegra. Em nenhum momento dissemos que erros não devem ser corrigidos, estamos chamando atenção para forma de corrigi-los, superá-los...

Agora, discutiremos, nossa terceira categoria, a cooperação entre os alunos, já começamos afirmando que tal cooperação não é trivial, ou seja, não é fácil ser alcançada, 
visto que no ensino tradicional, o que menos se precisa são alunos cooperativos.

Rodrigues [22] ainda nos alerta, "[...] apenas colocar alunos para trabalharem em grupo não é garantia de interação entre eles, muito menos certeza de cooperação, ou perda de egocentrismo. A tão desejada cooperação e o efetivo trabalho com seus pares surgirão se eles tiverem uma atividade interessante que precise realmente da participação de todos" (p.33).

Então o caminho realmente é propor atividades empolgantes, desafiadoras, onde a participação coletiva seja fundamental, indispensável.

No que tange à avaliação, não podemos encará-la numa visão construtivista como classificatória, ela deve ser interpretada como instrumento de aprendizagem e, portanto, deve estar presente em todas as fases do ensino, ou seja, a todo o momento os alunos devem ser avaliados: na manipulação dos objetos, na interação com os demais estudantes, na proposição de hipóteses, nas explicações causais. As respostas dos alunos não devem ser comparadas com o propósito de ver qual foi a mais completa, mais eficiente, mas devem ter um intuito investigativo. Exemplifico. Admitindo que a resposta de João foi excelente e que a de Bernardo foi razoável, que encaminhamentos o professor poderia propor a Bernardo, para que ele possa construir seu conhecimento, superando assim suas dificuldades [22]?

Nossa, quinta e última categoria, trata da interação professor-aluno, defendemos um ambiente onde exista a cumplicidade e respeito entre professores e alunos. É preciso que as questões propostas pelos alunos sejam ouvidas, que suas explicações sejam escutadas, mesmo que possam estar erradas. Escutar respostas errôneas, não significa aceitá-las como verdades absolutas, significa que a partir destas iremos avançar para construção de respostas aceitas na comunidade cientifica. Não é um corrigir, por corrigir e sim um corrigir para construir.

Nossos alunos precisam de um espaço em que seu desenvolvimento seja permitido, para tanto é necessário que estes realmente escutem, interajam com seus professores, desta forma cumplicidade e respeito estarão garantidos.

Como nossa proposta inclui o ensino da Matemática vinculada a Física, fomos buscar em Pietrocola [26] o entendimento da matemática como linguagem estruturante do pensamento físico. Tal autor relata quem em suas pesquisas, que a Matemática é apontada com grande responsável pelo fracasso escolar no que tange ao ensino de Física, ou seja, os estudantes não sabem Física pois não sabem Matemática, isto reafirma o que pensam um número significativo de professores de Física que conhecemos.

Mas, a concepção de que saber Matemática é prérequisito para entender Física, também reflete-se no Ensino no Superior, basta olhar os currículos de Física das IES. Essa análise simplória mascara o verdadeiro problema, como a Matemática deve ser ensinada quando se pretende utilizá-la nas aulas de Física [26].
Esta última reflexão nos aponta dois caminhos pelos quais o ensino da Matemática na Física permite a aprendizagem de conteúdos físicos: o domínio técnico dos sistemas matemáticos e a capacidade de utilizar os saberes matemáticos para estruturação de situações físicas. O primeiro caminho trata da operação de algoritmos, solução de equações ... e são designados de habilidades técnicas; já o segundo esta vinculado ao uso organizacional, discriminado como habilidade estruturantes [26].

Fizemos a opção pelo segundo caminho, visto que este só pode ser obtido dentro do ensino de Física, logo temos ai uma intenção didático-pedagógica que foi utilizada em especifico nestas atividades desenvolvidas junto aos alunos.

\section{Metodologia de trabalho}

A atividade que passamos a relatar foi aplicada para alunos do $1^{\circ}$ ano do Ensino Médio de uma escola pública situada em uma cidade do sul do Rio Grande do Sul. Nesta etapa da Educação Básica, os estudantes já têm a clareza da divisão de espaços entre as disciplinas em sua carga horária, aceitando-a sem nenhum tipo de crítica, uma vez que todo o sistema escolar trabalhou-os para criar tais compartimentos em sua aprendizagem, fisicamente definidos como 'cadernos'.

Para borrar as divisões destes compartimentos, inicialmente os alunos foram avisados que a forma de trabalho seria distinta da que eles estavam acostumados, com algumas tarefas determinadas, mas não fixas. A tarefa a ser executada era a construção de um espelho parabólico. Brietzke apresenta de maneira formal a resolução da equação diferencial e a interpretação da solução, sob o ponto de vista estrito matemático, mas sempre chamando a atenção para a aplicação na construção do espelho [27]. Um relato do procedimento, seguindo a forma da equação diferencial e criado a partir de um molde com resina e fibra de vidro é apresentado em [28], com objetivos de ensino, tanto básico como superior. Obviamente, alunos no $1^{\circ}$ ano do Ensino Médio não têm ainda o desembaraço matemático para entender e calcular uma equação diferencial, por isso o trabalho a partir das funções definidas.

Foram oportunizados três encontros, cada encontro foi constituído de dois períodos e cada período teve uma duração de 50 minutos. A seguir apresentaremos cada encontro.

\subsection{Primeiro Encontro}

Voltando ao nosso procedimento, após apresentada a tarefa, cada grupo recebeu réguas grandes, lápis, borracha e papel branco de dimensões de uma cartolina. A utilização da cartolina ficou a critério dos grupos, a partir de algumas instruções dadas pelo professor, esboçadas no quadro: primeiro, o traçado de um segmento de reta paralelo a uma das bordas do papel e depois, a marcação de um ponto fora desse segmento, numa posição mais ou 
menos na altura da metade do segmento, a uma distância escolhida pelo grupo.

Inicialmente, alguns alunos perguntaram sobre a adequação da distância escolhida por eles, mostrando a preocupação com a correção do trabalho. Nesse momento, foram orientados a não esboçar o ponto isolado muito próximo do segmento de reta construído, pois isso dificultaria a tarefa seguinte. Após a realização da primeira etapa da dinâmica, foi solicitado aos alunos à marcação de trinta novos pontos, obedecendo a seguinte regra: cada ponto a ser colocado deveria ficar equidistante do segmento de reta esboçado e do ponto inicial. Por exemplo, se um ponto novo estivesse a $5 \mathrm{~cm}$ do ponto inicial, também deveria estar a $5 \mathrm{~cm}$ do segmento de reta traçada inicialmente.

Esta regra criou aparentes dificuldades aos alunos, o que fez com que os primeiros pontos levassem um tempo considerável a serem obtidos, uma vez que a exigência da regra aparentava ser algo difícil de cumprir. Além disso, os alunos argumentaram que a quantidade de pontos exigidos tornava a tarefa quase impossível. Ao final da atividade, porém, percebemos que foram marcados muito mais pontos do que os inicialmente pedidos.

$\mathrm{Na}$ próxima tarefa da atividade, foi solicitado que os grupos ligassem esses pontos obtidos, buscando obedecer à curvatura que os mesmos sugerem. Esta etapa exigiu maior cuidado, para evitar a tendência de aproximar toda curva por segmentos de reta. A sugestão foi pedir aos alunos que traçassem segmentos de reta entre cada par de pontos contíguos e, ao final, contornassem a curva assim evidenciada. Com o conhecimento sobre funções quadráticas, desenvolvido nas aulas de Matemática (com outro professor), os alunos logo constataram que a curva esboçada era uma parábola.

Após obter a curva, utilizando os primeiros princípios, passamos para a atividade hands-on propriamente dita: a construção de um espelho curvo. Para isso, utilizamos lâminas de isopor, estiletes, cola, acetato e alfinetes. Esta etapa precisou ser cuidadosamente planejada, uma vez que os alunos deveriam montar um sólido de revolução, conceito pouco trabalhado na Matemática do Ensino Médio. Por isso, fixamos na sala de aula dois cartazes, para referência e auxílio: um mostrando o esqueleto de um parabolóide, representado por partes que deveriam ser feitas a partir das matrizes construídas pelos grupos; outro, mostrando o esqueleto de cilindro parabólico, representado de modo análogo ao parabolóide. Como os cartazes traziam representações planificadas, projetando um sólido de 3 dimensões no papel com 2, apresentamos a representação de arco de parábola feita de arame, girando em torno de um eixo imaginário, para que os alunos pudessem localizar-se espacialmente, obtendo assim um esquema para o primeiro modelo. Para completar a demonstração para esta tarefa, mostramos essa mesma representação de arco de parábola deslocando-se, sem girar, sobre um eixo que passa pelo vértice da parábola, perpendicularmente ao plano da mesma - efeito da translação de eixos. A Figura 1 apresenta as imagens que estavam nos dois cartazes que foram utilizadas em aula.

Neste ponto, fizemos a primeira etapa de discussão e crítica sobre a atividade. Esta etapa foi importante para acompanhar o desenvolvimento da turma, bem como mapear suas dificuldades. Além disso, oportunizou-se tempo para os alunos discutirem que modelo seria seguido. Assim foi concluída a primeira parte da tarefa, realizada em sala de aula. Com o modelo definido, a próxima etapa do trabalho deveria ser realizada fora do espaço da aula, podendo ser feita na casa dos estudantes. Nesta etapa, os alunos precisariam ter tranquilidade para construir as partes constituintes do esqueleto do espelho, por isso não realizá-la em sala de aula, com tempo definido para início e fim da atividade. Solicitamos aos alunos que as dúvidas e problemas verificados na montagem fossem anotados e relatados no próximo encontro em sala de aula, na semana seguinte.

\subsection{Segundo Encontro}

Apenas para registro, cabe apontar alguns dos relatos que surgiram na aula seguinte, que foram a dificuldade de cortar o isopor; o receio em cortar o acetato (medo de errar); a dificuldade na fixação do acetato junto ao isopor, pois o mesmo deveria ficar perfeitamente liso; a percepção que aquecendo o estilete, os cortes no isopor ficariam mais precisos. A partir destes relatos, iniciamos a parte final da atividade, com as conclusões alcançadas através da mesma.

As Figs. 2 e 3 mostram alguns exemplos dos espelhos construídos. Como forma de mostrar alguns princípios da Óptica Geométrica, os grupos foram convidados a levar seus espelhos para o pátio da Escola, na primeira parte da aula. Após a explicação sobre a propagação da luz, mostrando sua reversibilidade e independência, os grupos foram orientados a deixar seus espelhos voltados na direção do Sol por alguns instantes. Apesar da questão da reflexão da luz nos espelhos ainda não ter sido discutida, foi solicitado a um membro de cada

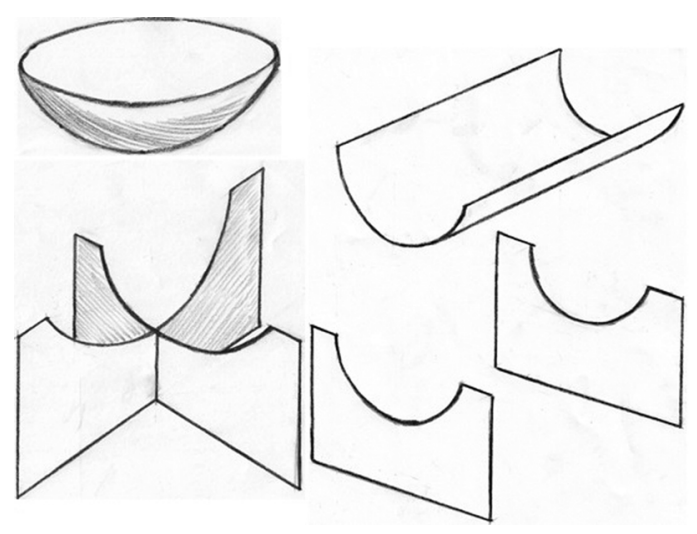

Figura 1: Representações dos esqueletos de parabolóide (esquerda) e cilindro parabolóide (à direita). Fonte: Acervo pessoal do pesquisador 


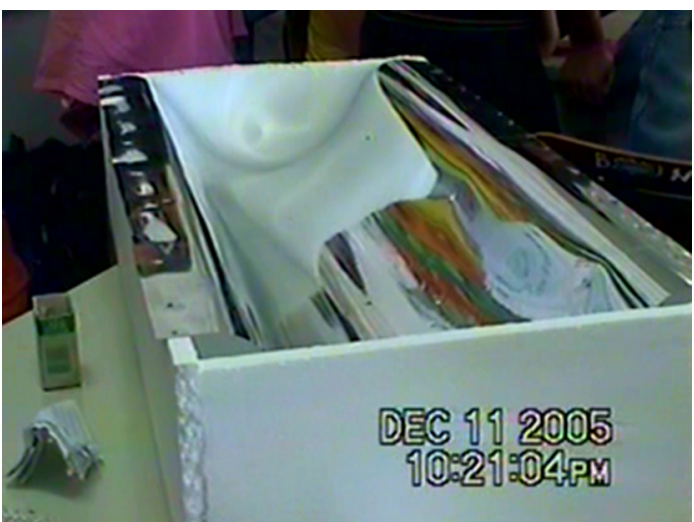

Figura 2: Espelho no formato de um cilindro de parabolóide. Fonte: acervo pessoal do pesquisador

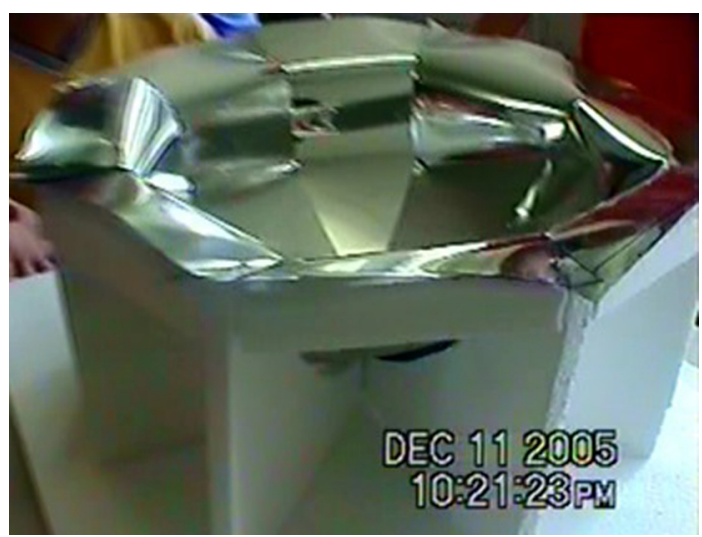

Figura 3: Espelho com formato de parábola. Fonte: Acervo pessoal do pesquisador

grupo que colocasse um dos dedos na posição que deveria estar o primeiro ponto representado na primeira tarefa da atividade, recomendando que não se mantenha muito tempo nesta posição. Os alunos foram surpreendidos pelo fato do dedo começar a esquentar. Esse processo rápido abriu caminho para a discussão sobre a reflexão da luz em sala de aula.

Aproveitando o fato observado pelos grupos, apresentamos o conceito de foco de um espelho. Na situação em questão, os raios de luz solar podiam ser considerados como paralelos ao eixo do espelho, pela distância entre Sol e Terra. Ao incidir sobre a superfície do espelho, todos eram desviados em direção de um ponto, denominado foco. A concentração dos raios solares ali provoca o aquecimento e explica como podemos colocar fogo num pedaço de papel usando uma lente (que funciona de forma semelhante ao espelho, mas deixando a luz passar através dela - refratar - no lugar de refletir). Lembrando o princípio da reversibilidade dos raios luminosos, invertemos o problema e mostramos que um objeto luminoso, ao ser colocado no ponto que marca o foco do espelho, tem seus raios refletidos de forma paralela ao eixo deste, podendo servir como um dispositivo de iluminação. Os alunos rapidamente fizeram a relação com o farol do carro, o que nos permitiu inferir um aprendizado mais significativo, uma vez que que se trouxe o conceito abstrato para uma aplicação real.

\subsection{Terceiro Encontro}

Para a etapa de discussão, devemos lembrar que buscamos introduzir o assunto da Óptica Geométrica a partir de uma abordagem com espelhos parabólicos. Nosso foco, neste trabalho, estava justamente na interface entre a Matemática usada para a construção do espelho e a Física responsável pelo fenômeno experimentado no pátio da escola.

Tendo isso como ponto de partida, duas questões foram propostas aos alunos: "Qual o nome do tipo de curva que vocês desenharam, como base para construírem o aparelho?" e "Para que pode servir este tipo de equipamento?". Estas questões foram lançadas para discussão nos grupos, por um tempo de 10 minutos. Após, passamos a fase de socialização, mediada pelo professor, para que os grupos pudessem trocar suas respostas e opiniões. Devemos notar que estas discussões estavam centradas nos conceitos e aplicações dos mesmos para os alunos. Aqui já podíamos perceber que a ideia da construção da parábola como lugar geométrico de pontos equidistantes teve uma aceitação muito maior pelos alunos do que o conceito livresco, pura e simplesmente. Isso já mostrou o acerto de escolher atividades hands-on para ensinar conceitos abstratos, como os tratados na Matemática.

Nosso próximo passo, continuando as atividades, voltouse para a percepção da relação algébrica existente entre as distâncias dos pontos da curva desenhada em relação a um sistema de ordenadas. Para isso, os alunos foram instruídos a traçar dois eixos sobre a curva obtida, que por simplicidade foram chamados de eixo-x e eixo-y. Em seguida, foram orientados a montar uma tabela de números a partir dos pontos que desenharam. Cada ponto deveria ser identificado pela sua coordenada relativa aos eixos x e y, numa organização Cartesiana, e completavam a tabela com o valor do quadrado de x. Completadas as três colunas, propusemos ainda o acréscimo de uma quarta coluna, onde seriam representados os resultados das razões entre os valores da segunda coluna e os da terceira, isto é, $\mathrm{y} / \mathrm{x} 2$.

Para esta última coluna, solicitamos que os cálculos fossem arredondados na segunda casa decimal. Já na obtenção da quarta linha da tabela, um dos grupos relatou que "algo estranho" estava acontecendo: "Professor, tá tudo errado, os cálculos dão sempre o mesmo valor!". Percebemos ali a oportunidade de uma orientação significativa, aproveitando esta constatação dos alunos, de maneira a mostrar que os cálculos estavam corretos. Para manter o espaço de investigação e reconhecimento dos padrões, passamos a questionar a turma sobre o significado deste acontecimento. Como auxílio, e aproveitando a ocasião para trabalhar a ideia de equação, solicitamos que os alunos isolassem a variável denotada por y em um dos cálculos, verificando o que estava sendo obtido. 
Seguindo estas recomendações, cada grupo teve a oportunidade de mostrar o resultado obtido no quadro, para socializar sua resposta. Na apresentação, solicitamos que os mesmos seguissem esta ordem: inicialmente o resultado encontrado para a razão y/x2, depois a expressão y/x2 = resultado, que depende do que cada grupo obteve; o valor de y isolado ( $\mathrm{y}=$ resultado $\mathrm{x} 2$ ) e finalmente apresentar a curva obtida.

Após as apresentações, seguiu-se mais uma etapa de discussões sobre o que havia sido construído pelos grupos. A função polinomial de $2^{\circ}$ grau, aprendida como conceito pelo livro de Matemática, passava a ter um significado real, com uma aplicação realizada pelos alunos. O fato de que os resultados de cada passo terem diferentes valores segundo os grupos, mas manterem o mesmo valor para todos os pontos do grupo permitiu aos alunos entender o significado do coeficiente da parábola,

$$
y=a x^{\wedge} 2
$$

relacionado à distância inicialmente escolhida pelos alunos entre o primeiro ponto marcado e o segmento de reta. Esta frutífera discussão, que alcançou os objetivos inicialmente previstos, completou o trabalho com os alunos, partimos agora para a análise de seus comentários e opiniões, entretanto para finalizar apresentamos a tabela 1 com o resumo das atividades desenvolvidas por encontro.

\section{Análise dos comentários e das opiniões dos estudantes.}

Agora utilizaremos a análise temática, a partir dos fatores elencados como necessários para propiciar um ambiente construtivista favorável a aprendizagem. Braun e Clarke [8] defendem que sua utilização oferece uma abordagem mais flexível e acessível para analisar dados qualitativos. Como corpus de análise, tomamos as gravações em vídeo das atividades desenvolvidas em sala de aula, assim como os registros dos cálculos, as curvas traçadas no papel e os espelhos parabólicos construídos pelos alunos. Traremos para nossa análise, os cinco pontos indispensáveis, segundo Carvalho, para uma metodologia de ensino com enfoque construtivista: a autonomia do aluno; o papel do erro na construção do conhecimento; a cooperação entre os alunos; a avaliação; a interação professor-aluno
Inicialmente, vamos analisar a cooperação entre os alunos: o que as vezes passa desapercebido, ou não recebe grande importância, é o produtivo trabalho em grupo, às vezes harmonioso, às vezes tumultuado; ao colocar a "mão na massa", os alunos cooperam para a realização da atividade, discutindo os pontos controversos e auxiliandose nas dificuldades levantadas. Mesmo as discordâncias ocorrem no ambiente do grupo, buscando entender e corrigir possíveis erros, e não entre os grupos, desta forma alunos que possivelmente tenham um nível de desenvolvimento real menor quando comparados aos colegas do grupo conseguem interagir, isto ficou nítido quando da execução e resolução das atividades, onde alunos dentro dos grupos solicitavam ajuda dos colegas. Por exemplo, quando o resultado da razão y/x2 começou a ser sempre o mesmo, um dos integrantes, que discordava dos resultados, refez todos os cálculos, achou o mesmo resultado, ainda não convencido solicitou ajuda do grupo e percebeu realmente que seus colegas de grupo tinham razão, demonstrando não aceitar passivamente a resposta. Existiu também a interação entre componentes de grupos distintos, já na realização das tarefas do primeiro encontro, onde um determinado grupo não conseguia obter os pontos, verificamos ao analisar as filmagens que dois integrantes de um determinado grupo deslocaram-se até outro para ajudar na construção dos pontos e mais, estes desenvolveram uma forma de obtenção de pontos através de outras retas auxiliares, conforme mostra a figura abaixo.

A Figura 4 acima mostra o sistema de retas auxiliares proposto por um determinado grupo para obtenção dos pontos equidistantes; segundo este grupo, "ao traçar uma reta auxiliar, todos os pontos desta reta estão a mesma distância da reta inicial, logo professor basta achar esta mesma distância em relação ao ponto inicial". Vamos exemplificar o raciocínio dos alunos: traçamos uma reta inicial, logo após marcamos um ponto a $5 \mathrm{~cm}$ acima da mesma, agora acima deste ponto traçamos por exemplo uma reta auxiliar que esta a $7 \mathrm{~cm}$ da reta inicial, então qualquer ponte sobre esta reta esta a $7 \mathrm{~cm}$ da reta inicial, logo partindo do ponto base, ou seja, tomando este como origem, posicionamos nossa régua até obter sobre a reta auxiliar um ponto a $7 \mathrm{~cm}$.

Aqui surge a categoria autonomia do aluno, tanto de sua aprendizagem quanto das próprias rotinas de ensino na sala de aula. Possivelmente a atitude destes dois alunos relatada nos parágrafos anteriores não aconteceria em

Tabela 1: Atividades desenvolvidas em cada encontro e tempo utilizado para a realização das atividades.

\begin{tabular}{lll}
\hline Encontros & Atividades & Tempo utilizado \\
\hline $1^{\circ}$ & $\begin{array}{l}\text { Obtenção dos pontos; apresentação e confecção dos moldes dos espelhos parabólicos; } \\
\text { discussões a respeito das atividades }\end{array}$ & 2 períodos \\
\hline $2^{\circ}$ & $\begin{array}{l}\text { Utilização dos espelhos construídos pelos estudantes no pátio e sala de aula; } \\
\text { apresentação de conceitos físicos pelo professor; discussões a respeito das atividades }\end{array}$ & 2 períodos \\
\hline $3^{\circ}$ & $\begin{array}{l}\text { Retomada das discussões sobre a curva obtida; traçar 2 eixos sobre a curva obtida, } \\
\text { montagens de tabelas; obtenção e arredondamento de valores. Observação do }\end{array}$ & \\
\hline & conceito construído
\end{tabular}




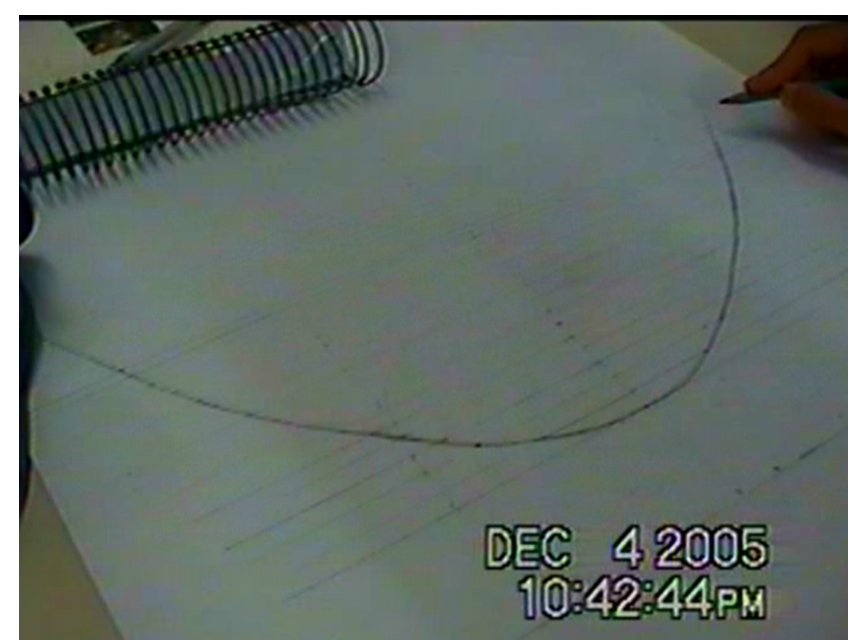

Figura 4: Obtenção dos pontos utilizando retas auxiliares. Fonte: Acervo pessoal do pesquisador.

um ambiente tradicional de aula, onde a aula magna [29] resume-se a um monólogo do professor, e os resultados são sempre apresentados prontos. A posição assumida pelos alunos, de participação no processo, permite-nos sugerir que o assunto teve significado para ele, aprendendo-o e não simplesmente compreendendo-o. Existiram outras situações que caracterizam autonomia, como a própria construção dos pontos, onde os alunos decidiam quais distâncias iriam adotar; no fato de discutirem e decidirem que modelo de espelho iriam construir, se o paraboloide ou o cilindro paraboloide.

Embora não estivéssemos junto aos alunos, durante a confecção dos espelhos, pelas suas falas observamos que até mesmo no ato de construir seus espelhos a questão da autonomia aflorou, quando estavam escolhendo que instrumentos utilizar, ou até mesmo que materiais dispor e algum adulto ou membro externo tentava opinar eles questionavam o motivo da sugestão.

Quando nos deparamos, com o papel do erro neste tipo de metodologia, notamos que a correção deste deve ser transformado numa situação de aprendizagem. Para exemplificar trazemos algumas situações presenciadas: ao discutir junto os alunos a relação do coeficiente a com a abertura da parábola construída pelos grupos, alguns alunos disseram que não existia relação e que tratava-se de apenas mais um número sem significado, todavia ao colocar no quadro as curvas obtidas, as tabelas e chamar a atenção para as possíveis relações existentes, fico claro para estes tais relações e logo transformamos um erro em situação de aprendizagem.

Outra situação bastante interessante, relacionada a erro, surgiu quando estávamos utilizando os espelhos no segundo encontro, onde um dos grupos afirmava veementemente que seu espelho não funcionava, pois o dedo colocado no foco não aquecia. Chamamos os outros grupos para participar da discussão, antes de abrir a discussão para o grande grupo pedimos aos alunos cujo o espelho não funcionava, para observarem os outros es- pelhos construídos, foi durante estas observações que um dos integrantes do grupo falou: - professor o nossa esta enrugado! Ou seja, não tinha caprichado na fixação do acetado - material refletor. Se estivéssemos em uma aula tradicional, possivelmente este erro teria sido conduzido de outra forma.

Queremos chamar a atenção para o fato de que o erro é aceitável neste tipo de metodologia, contudo devemos proporcionar situações onde este poderá ser discutido, analisado e por fim corrigido.

Antes de analisarmos as categorias: interação professor - aluno e avalição, daremos uma atenção mais do que merecida para a capacidade que a Matemática tem de nos proporcionar o estudo de situações físicas. Ao nos debruçarmos sobre esta questão, verificamos que trabalhar com as aplicações dos espelhos parabólicos permitiu surgirem sugestões sobre a utilização dos espelhos parabólicos como aquecedores, o que levou a pensarem sobre questões ligadas ao meio ambiente e ao desenvolvimento sustentável. Além disso, questões associadas à Astronomia e às Telecomunicações, como o uso de antenas de rádio frequência ou os telescópios astronômicos e o fato deles serem constituídos por espelhos parabólicos, surgiram para manter os alunos interessados na discussão e no desenvolvimento das aulas. Mas tudo isso surgiu, teve origem em um molde de espelho, confeccionado a partir da construção de pontos para obtenção de uma curva que conhecemos por parábola, ou seja, a Matemática contribuindo na origem de situações físicas.

A avaliação, é um assunto que preocupa todo professor, na metodologia construtivista não é diferente, acreditamos que ao adotar este tipo de metodologia nossa avaliação não pode continuar a mesma, ela deverá ser diária, claro que acarreta mais trabalho, todavia será mais completa. Perguntamos: alunos que participam de todas as atividades propostas, já não estão sendo avaliados? Quando verificam a relação entre coeficiente e abertura da parábola, não mostram que construíram, isto não serve como avaliação? Tudo bem, isso, é construção em Matemática e queremos verificar Física! E quando o aluno observa, não, melhor, sente o dedo esquentar ao colocá-lo no foco do espelho e relaciona com o ponto inicial que deu origem a sua parábola ela, já não poderia estar sendo avaliado?

Queremos afirmar que podemos propor metodologias novas e continuar com os velhos sistemas de avalição, aqui não apresentamos de forma direta uma crítica ao sistema de avaliação tradicional, apenas chamamos a atenção de conciliar métodos e sistemas de avaliar.

Chegamos a última categoria, interação professor aluno, para começar a analisá-la trazemos a seguinte situação presenciada em aula: durante as discussões que seguiram à exposição dos espelhos montados à luz solar, um dos alunos relatou que havia sentido a luz ser refletida na direção de seu dedo, e passava a entender como ocorria a propagação de calor por radiação. Aproveitamos o espaço para trabalhar a ideia desta propagação, 
introduzindo os conceitos básicos sobre a radiação eletromagnética, aproveitando o interesse despertado pelas atividades. Este simples exemplo tem o objetivo de mostrar afinidade professor-aluno, ou seja, o estudante relata sua compreensão sobre determinado assunto e o professor a partir desta dá prosseguimento nos conteúdos. Aproveitamos este simples relato, para desmistificar um comentário, que classificaríamos como infeliz, que surge a respeito da prática construtivista, o que importa é desenvolver o raciocínio, o conteúdo é secundário. Este tipo de comentário reflete uma concepção errada da visão piagetiana, pois desenvolver o raciocínio não é preocupação única, pois desenvolver o raciocínio significa que os sujeitos devem ter condições de chegar ao raciocínio formal, caraterístico do estádio em que somos capazes de realizar operações sobre operações, formular hipótese, trabalhar abstrações [30]. Ainda, o equivoco gerado pelo slogan em questão leva, no mínimo, à insegurança entre professores: se os conteúdos escolares não são importantes, o que devem ensinar nas aulas? E como fazer para desenvolver o raciocínio de seus alunos sem um conteúdo que lhe dê suporte?

Quando notamos que os alunos estavam percebendo uma relação algébrica abstrata que simboliza e identifica as relações numéricas que aparecem na figura que desenharam, fiquei sem ação. É necessário salientar, que através da observação dos desenhos, feitos pelos colegas, eles conseguiram verificar por si mesmos, a relação entre a constante a, na Eq. (1), e a concavidade da curva. Além disso, perceberam que as diferenças nas distâncias escolhidas inicialmente significavam diferentes constantes a.

\section{Conclusões e considerações}

Este trabalho já foi aplicado várias vezes, geralmente utilizamos de seis a oito períodos para conclui-lo na íntegra. Mas o fato de não sabermos com precisão o tempo que será utilizado, não deve ser motivo para não ser colocado em prática. Sob este ponto de vista, esta proposta é construtivista na origem [22] e o professor deve estar preparado para auxiliar no desenvolvimento dos alunos durante a realização das atividades. Outro aspecto importante, que não foi alvo de discussão, mas deve ser levado em consideração, é o poder aquisitivo do contexto onde trabalhamos. A realização destas atividades constitui um custo considerável, que determinadas comunidades escolares não poderão arcar.

Além disso, pudemos comprovar que é possível trabalhar disciplinas distintas em conjunto, mesmo com o envolvimento de um único professor. Ou seja, um professor de Física, cuja formação inicial esta recheada de cadeiras de Cálculo [26] poderá promover a integração entre Matemática e Física.

Verificamos, também, que os alunos são capazes de construir algo material, concreto, na realização das atividades hands-on; quando bem orientados, contudo, são capazes de construir conceitos, realizar tarefas e desenvolver habilidades; isso foi observado em nossa discussão dos resultados obtidos. Participando do processo ensinoaprendizagem com trabalhos deste estilo, percebemos propiciar situações para a verdadeira aprendizagem e não ser apenas um banco de dados. Isso pode ser alcançado pelo entendimento da aplicação dos estudos a aspectos práticos do cotidiano dos alunos.

O parágrafo anterior nos oportuniza uma pequena discussão sobre um slogam muito difundido quando o assunto é construtivismo, O papel do professor é o de facilitador da aprendizagem, ele não deve interferir, mas deixar o estudante descobrir sozinho. Não concordamos com tal afirmação, pois pode levar a compreensão de que o ato de ensinar é negativo, ou seja, quando o professor ensina não permite que o estudante construa seu conhecimento [30]. Proporcionar situações para promover a aprendizagem, não pode substituir o ato de ensinar [31], o que se deseja é que o professor deixe de ser apenas um conferencista e que estimule a pesquisa e o esforço, ao invés de se contentar com a transmissão de soluções já prontas (...). Seria absurdo imaginar que, sem uma orientação voltada para a tomada de consciência das questões centrais, possa a criança chegar apenas por si a elaborá-las com clareza.

Então com este tipo de proposta não queremos que o professor deixe de ensinar, gostaríamos de diminuir o verbalismo na transmissão dos conteúdos, promover a pesquisa facilitando o ato inventar ou reinventar. Não queremos que o aluno ganhe tudo mastigado, onde a mera função da classe seria a de ouvir o professor, pois quando promovemos o diálogo, a crítica, construímos coletivamente.

Para finalizar trazemos para uma pequena discussão do chavão popular, ou slogam, a respeito do construtivismo, o professor construtivista trabalha o que o aluno traz de casa. Na nossa proposta em si realmente, trabalhamos o que os alunos trouxeram de casa, o espelho. Mas, o que eles trouxeram já estava determinado de ser trazido e serviu em muito para ampliar seu conhecimento do cotidiano. Faremos uma pequena comparação entre conhecimento cotidiano e conhecimento cientifico, o primeiro trata da experiencia imediata, ou seja, servem para solucionar problemas práticos; já o segundo busca a veracidade. Então os conhecimentos do cotidiano servem de ponto de partida e portanto precisam ser superados, não no sentido de desqualifica-los e sim suas ideias devem ser trabalhadas para que atinjam o âmbito das ideias cientificas. Resumidamente, afirmamos que para atingir a evolução das ideias para o âmbito cientifico, um componente é indispensável, o conteúdo, pois eles alimentam as estruturas mentais, promovendo sua progressão, De forma bem trivial, devemos considerar a realidade do aluno, todavia devemos propor situações para superar tais realidades. 


\section{Referências}

[1] L. Menezes, in: Anais do Encontro Nacional de Professores de Matemática - ProfMat, Portimão, Portugal (1999), disponível em http://www.ipv.pt/millenium/20_ect3. $\mathrm{htm}$, acesso em 15 de setembro de 2016.

[2] Brasil, Matriz de Referência do Exame Nacional do Ensino Médio (Instituto Nacional de Estudos e Pesquisas Educacionais Anísio Teixeira, Brasília, 2011).

[3] H.A. Gonçalves, O Conceito de Letramento Matemático: Algumas Aproximações, disponível em http://www.ufjf. br/virtu/files/2010/04/artigo-2a14.pdf acesso em 23 de setembro de 2015.

[4] R. Dawes, Suggestive Hints Towards Improved Secular Instruction, Making it Bear Upon Practical Life (Groombridge \& Sons, Londres, 1861), 8th ed, 258 p.

[5] D. Layton, Physics Education 8, 19 (1973).

[6] W. Wuo, A Física e os Livros: Uma Análise do Saber em Física nos Livros Didáticos Adotados para o Ensino Médio (EDUC/FAPESP, São Paulo, 2000).

[7] F.C. Pereira e E. Schuhmacher, Aprendizagem Significativa em Revista 3, 22 (2013).

[8] V. Braun e V. Clarke, Qualitative Research in Psycology 3, 77 (2006).

[9] P. Perrenoud, Construir as Competências Desde a Escola (Artes Médicas, Porto Alegre, 1999), 96 p.

[10] J.M. Moran, Mudar a Forma de Ensinar e de Aprender com Tecnologias, disponível em http://www.eca.usp.br/prof/moran/site/textos/ tecnologias_eduacacao/uber.pdf, acesso em 15 abril de 2004.

[11] C.N. Fino, in: Pesquisar Para Mudar (A Educação), editado por C.N. Fino e J.M. Sousa (Universidade da Madeira, Funchal, 2011), p. 29-48.

[12] E.V. Roberto, Aprendizagem Ativa em Ótica Geométrica: Experimentos e Demonstrações Investigativas. Dissertação de Mestrado, Instituto de Física de São Carlos, Universidade de São Paulo, São Carlos, 2009.

[13] B.V. da Cruz Silva e A.F.P. Martins, Experiências no Ensino de Ciências 5, 71 (2010).

[14] R.A. Martins e A.P. Bispo da Silva, Revista Brasileira de Ensino de Física 31, 1605 (2013).

[15] J.P. Gircoreano e J.L.A. Pacca, Caderno Catarinense de Ensino de Física 18, 26 (2001).

[16] V.A. Almeida, C.A. Cruz e P.A. Soave, Concepções Alternativas em Óptica. Textos de Apoio ao Professor de Física 18(2) (Instituto de Física, Porto Alegre, 2007), 76 pp.

[17] A.M. dos Santos Júnior, in: Anais do XII Encontro Brasileiro de Estudantes de PósGraduação em Educação Matemática, disponível em www2.rc.unesp.br/eventos/matematica/ ebrapem2008/upload/275-1-A-GT8_medeiros_ta.pdf, acesso em 12 de abril de 2014.

[18] G. Vergnaud. Recherches en Didactique des Mathématiques 10, 133 (1990).

[19] R.M. Sousa, O Uso do Geogebra no Ensino de Função Quadrática. Dissertação de Mestrado Profissional em Matemática, Programa de Pós-Graduação Matemática em Rede Nacional, Universidade Federal do Oeste do Pará, 2014.
[20] A.R. de Souza e G.A. da Silva, Revista Zetetike 14, 127 (2006).

[21] U. D'Ambrosio, Educação Matemática em Revista 11, 14 (2001).

[22] M.A.T. Rodrigues, Metodologia Construtivista no Ensino de Física para Discentes do Curso de Pedagogia. Dissertação de Mestrado Profissional de Ensino de Física, Instituto de Matemática, Estatística e Física, Universidade Federal do Rio Grande, Rio Grande, 2015.

[23] A.M.P. de Carvalho, Física: Proposta de Ensino Construtivista (Editora Pedagógica Universitária, São Paulo, 1989).

[24] Brasil, Parâmetros Curriculares Nacionais para o Ensino Médio. Ciências da Natureza, Matemática e suas Tecnologias (MEC/SEMTEC, Brasília, 2000).

[25] L.A. Brettas, Pesquisa e Produção de Novos Materiais Para o Ensino de Matemática. Tese de Doutorado em Engenharia de Produção, Programa de Pós-Graduação em Engenharia de Produção, Universidade Federal de Santa Catarina, Florianópolis, 2005.

[26] A.M.P. Carvalho, A.I. Vannucchi e M.A. Barros, Ciências no Ensino Fundamental: O Conhecimento Físico (Scipione, São Paulo, 2009).

[27] A.M.P. de Carvalho, Ensino de Física - Coleção Ideias em Ação (Cengage Learning, São Paulo, 2010).

[28] E.H.M. Brietzke, Espelho Parabólico, disponível em http: //www.mat.ufrgs.br/ brietzke/esp/esp.html, acesso em 14 de outubro de 2012

[29] L.A.N. de Paula, P. Raggio e A.K.T, Assis, http://arxiv.org/0810.4165, acesso em 24 de maio de 2015.

[30] F. Imbernón, Inovar o Ensino e a Aprendizagem na Universidade (Ed. Cortez, Rio de Janeiro, 2012), $1^{\text {a }}$ ed.

[31] C.R.S.L. Chakur, R.C. da Silva e V.G. Massabni, in: Anais da 27a Reunião Anual da ANPed, disponível em http://27reuniao.anped.org.br/gt20/t203.pdf acesso em 21 de abril de 2017.

[32] J. Piaget, Para Onde Vai a Educação? (Livraria José de Olympio, Rio de Janeiro, 1977). 